\title{
Dimensional Changes of Record Base for Complete Denture
}

\author{
Ahmed MA Hussain \\ BDS, MSc (Assist Lect)
}

\author{
Ahmed A Al-Ali \\ BDS, MSc (Lect)
}

Zeina M Ahmad

BDS, MSc (Assist Lect)

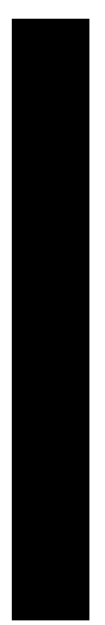

\begin{abstract}
Aims: The aims of this study are to compare the dimensional changes of record base from heat and cold cured acrylic resin, with the latter cured by two techniques, and to study the regions vulnerable to dimensional changes. Materials and Methods: The adaptation of the record base on edentulous maxillary casts were tested by sectioning the record base-stone casts sets transversely and measuring the gaps with travelling microscope. The gaps represent the crest of the ridge, midline, and the deepest points of buccal sulcus. Results: Record base made from cold cured acrylic resin showed significantly higher dimensional changes than that from heat curd acrylic resin. There were no significant difference between the bench-curd and thermopress curing for cold cured acrylic resin. No significant differences found between the ridge crest and midline , but both show significantly less dimensional changes than the buccal vestibules. Conclusions: Curing cold cured acrylic resin by thermopress machine would not improve dimensional stability. And to improve the dimensional stability, the denture base that is made from heat cured acrylic resin may be used as a record base.

Key words: Dimensional change, record base, acrylic resin .
\end{abstract}

Hussain AMA, Al-Ali AA, Ahmad ZM. Dimensional Changes of Record Base for Complete Denture. Al-Rafidain Dent J. 2007; 7(SpIss): 5S-9S

Received: $27 / 8 / 2006$

Sent to Referees: 7/8/2006

Accepted for Publication: 19/9/2006

\section{INTRODUCTION}

One of the most important steps in the process of complete denture construction is taking vertical dimension of occlusion and centric relation. This step is basically depends on properly fabricated record base, a stable record base allows for efficient and accurate bite registration and recording vertical dimension of occlusion. Intimate adaptation of record base to the cast and dimensional stability of the record base after fabrication are important to ensure intraoral retention and stability of record base. This in turn will affect the accuracy of jaw relation record and the success of complete denture therapy ${ }^{(1,2)}$.

Historically, record base were fabricated from cold cured acrylic resin, despite the fact that the heat cure resin has superior biological, physical, and mechanical properties, cold cured acrylic resin are still in use ${ }^{(3,4)}$.

Acrylic resin complete dentures un- dergo dimensional changes during polymerization ${ }^{(5)}$. Denture base dimensional changes were found with commercial heat cured acrylic resin ${ }^{(6)}$. The pressure of the final closure may be released when the flask is removed from the mechanical press and placed in the spring clamp. This release in pressure may result in dimensional changes that distort the denture base $^{(7)}$. The dimensional changes in denture bases were influenced by the material and the procedure ${ }^{(8)}$. Discrepancies in the adaptation on the cast at the posterior border of the maxillary record base have been reported by several investigators and have been attributed to the linear dimensional change and volumetric shrinkage ${ }^{(9)}$.

The themopressing curing technique of the cold cured acrylic resin will improve the tensile and transverse strength and reduce the monomer contents of the resin ${ }^{(10)}$. The purposes of this study are to evaluate the thermopressing curing tech- 
nique on the dimensional stability of the record base made from cold cured acrylic resin compare to the bench curing technique, and to estimate the dimensional stability of the heat cure and the cold cured acrylic resin, and finally to measure the adaptation of the record base on three points on the maxillary cast. These points represent the crest of ridge, midline, and the deepest points of the buccal sulcus .

\section{MATERIALS AND METHODS}

Eighteen casts were poured in dental stone into edentulous molds. Stone material was mixed according to the manufacturer recommendations. Casts were removed from the molds after setting and allowed to dry, then covered with thin coat of cold mold seal and allowed to dry again. The materials and techniques that were used for the construction of record base are:

1. Heat cured acrylic resin (Major Prodotii Dentari S.P.A.,Italy) cured by water bath: The acrylic resin was cured by water bath $70^{\circ} \mathrm{C}$ for 30 minutes, then proceed at $100^{\circ} \mathrm{C}$ for 30 minutes (according to the manufacturer instruction) in thermostatically controlled water bath.

2. Cold cured acrylic resin (Major Prodotii Dentari S.P.A.,Italy) bench cured: The record base was bench cured after the resin sheet was placed in mold former to ensure uniform thickness, then adapted on the cast and the borders were trimmed.
3. Cold cured acrylic resin (Major Prodotii Dentari S.P.A.,Italy) cured by using thermopress machine (MINI 2000, FMD601CP001, Major Prodotii Dentari S.P.A.,Italy): A universal thermopress is a curing device for the polymerization of cold cure acrylic resin, temporary or permanent bridges and crowns in acrylic or composite material. The required cycle of time is (1-30) minutes, temperature $(40-120){ }^{\circ} \mathrm{C}$ and pressure (1-6) bar ${ }^{(10)}$.

The record base-stone cast sets were transversally sectioned into three sections, corresponding to the distal of canines, mesial of first molars, and posterior palatal zone ${ }^{(11)}$. The gap between the resin base and stone cast was measured at five points in the right and left ridge crests, at the midline, and at the deepest points of right and left buccal sulcus using travelling microscope (Zeiss/ Germany). The data were submitted to ANOVA and Duncan multiple range test at a significant level of $\mathrm{P}<0.05$.

\section{RESULTS}

The means of the dimensional change values of the maxillary record base made of heat cured acrylic resin and cold cured acrylic resin (which cured by the two methods: bench cure and thermopress) at three different points (which are the crest of ridge, midline, and the deepest points of buccal vestibule) are shown in Table (1).

Table (1): Means of dimensional changes

\begin{tabular}{ccc}
\hline Material & Region & Dimensional change (mm) \\
\hline \multirow{2}{*}{$\begin{array}{c}\text { Cold cured acrylic resin } \\
\text { (bench cured) }\end{array}$} & Buccal Sulcus & 0.2857 \\
& Crest of Ridge & 0.1116 \\
& Midline & 0.06696 \\
\hline \multirow{2}{*}{ Cold cured acrylic resin } & Buccal Sulcus & 0.2634 \\
(cured by thermopress) & Crest of Ridge & 0.08929 \\
& Midline & 0.1562 \\
\hline \multirow{2}{*}{ Heat cured acrylic resin } & Buccal Sulcus & 0.2143 \\
& Crest of Ridge & 0.000 \\
& Midline & 0.01786 \\
\hline
\end{tabular}

One way analysis of variance (ANOVA) was used to find the difference between the tested material and technique at different points. Table (2) showed that there was a significant difference among all of the interacted variables $(\mathrm{P}=0.000)$. 
Table (2): ANOVA test for all the interacted variables (materials, techniques, and regions)

\begin{tabular}{cccccc}
\hline Source of variance & Sum of squares & D f & Mean Square & F value & P-value \\
\hline Between Groups & 0.681 & 8 & 0.08514 & 11.964 & 0.000 \\
Within Groups & 0.448 & 63 & 0.007117 & & \\
\hline Total & 1.129 & 71 & & & \\
\hline
\end{tabular}

Df: degree of freedom

ANOVA for the tested materials and techniques indicates significant different between the variables $(\mathrm{P}=0.022)$ (Table 3$)$. Duncan multiple range tests (Figure 1) indicate that there was a significant difference between the heat cured and the cold cured acrylic resin, which express higher dimensional change values, but there was no significant difference between the bench cured-cold cured acrylic resin and the cold cured acrylic resin cured by thermopress

Table (3): ANOVA test for the effect of materials and techniques on dimensional changes

\begin{tabular}{cccccc}
\hline Source of variance & Sum of squares & D f & Mean Square & F value & $\boldsymbol{P}$-value \\
\hline Between Groups & 0.118 & 2 & 0.05889 & 4.016 & 0.022 \\
Within Groups & 1.012 & 69 & 0.01466 & & \\
\hline Total & 1.129 & 71 & & & \\
\hline
\end{tabular}

Df: degree of freedom

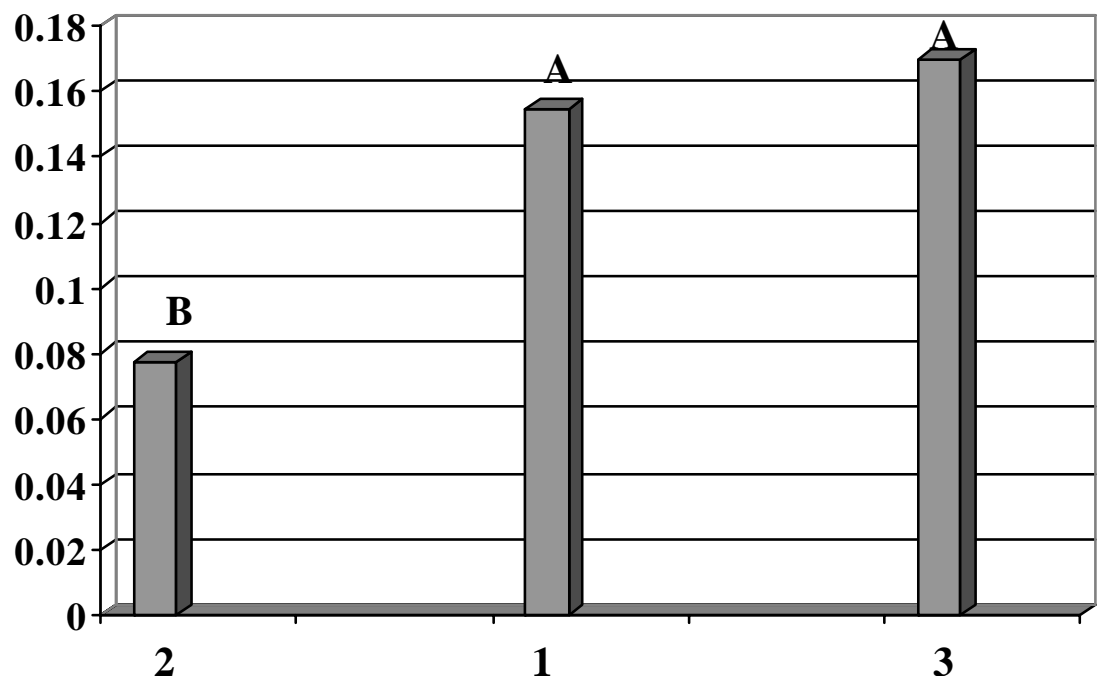

Figure (1): Duncan multiple range test $\mathrm{s}$ for the effect of materials and techniques on dimensional changes. 1: Cold cured acrylic resin (bench cured); 2: Cold cured acrylic resin (cured by thermopress); 3: Heat cured acrylic resin.

ANOVA for the amount of dimensional change at the three tested areas showed that there was a significant difference between the measured points $(\mathrm{P}=0.000)$ (Table 4). The deepest points of buccal vestibule express significantly the highest values of the dimensional change among the measured areas, and there was no significant difference between the crest of ridge and the midline (Figure 2). 
Table (4): ANOVA test for the effect of regions on dimensional changes

\begin{tabular}{cccccc}
\hline Source of variance & Sum of squares & D f & Mean Square & F value & P-value \\
\hline Between Groups & 0.304 & 2 & 0.152 & 14.505 & 0.000 \\
Within Groups & 0.471 & 45 & 0.01048 & & \\
\hline Total & 0.775 & 47 & & & \\
\hline
\end{tabular}

Df: degree of freedom

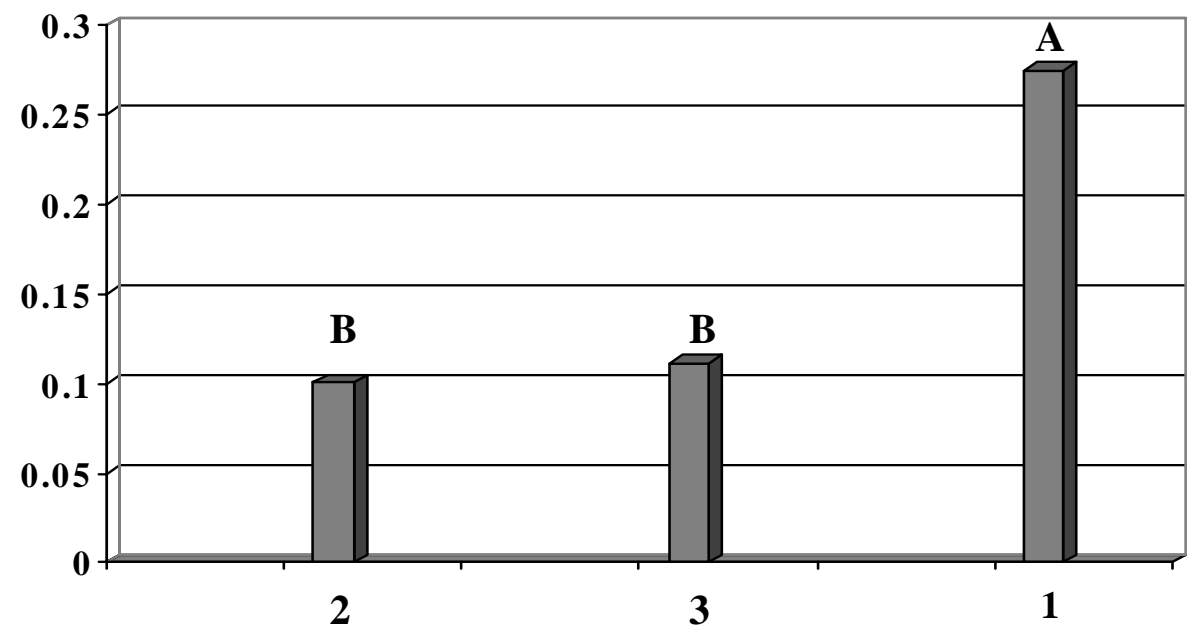

Figure (2): Duncan multiple range test for the effect of regions on dimensional changes.3: Midline; 2: Crest of ridge; 1: Buccal sulcus

\section{DISCUSSION}

This study of the dimensional change of the record base in relation to the maxillary cast shows that the cold cured acrylic resin undergoes significantly higher dimensional change value than the heat cured acrylic resin. The results agree with Consani et al., ${ }^{(12)}$ who found that there was a statically significant difference between the packing methods, and agree with Machado et al., ${ }^{(13)}$ who found that heat-treated specimens showed significant improvement of the long term dimensional stability. The heat cured acrylic resins shows lower dimensional change values compared to the cold cured acrylic resin. This may be due to the higher residual monomer content and the higher porosity level of the cold cured acrylic resin which lead to greater water absorption that causes greater dimensional instability ${ }^{(14)}$.

Although the bench cure technique shows lower dimensional change values than thermopress. The difference between the two tested curing techniques for the cold cured acrylic resin was insignificant. The results agree with Elahi and Abdullah
(15) who found that there were no significant difference in dimensional change between bench curing and curing under air pressure and curing under warm water and air pressure, And disagree the results obtained by Craige ${ }^{(16)}$ who stated that the cold cured acrylic resin processed in $45^{\circ} \mathrm{C}$ water vapor under 20psi pressure show minimum distortion. However, according to Elahi and abdulla ${ }^{(15)}$ denture base cured in this manner are dimensionally less stable than those cured at normal atmospheric pressure.

The greater amount of discrepancy was found to be at the deepest point of buccal vestibule. This is may be due to the excess heat generation during finishing, which is more noticeable at the borders, and distort the denture by releasing residual stress. El sheikh Hand Abdel Hakim (17) concluded that gap widths differed at different areas of the same base and gap width was not related to base thickness at any point, Elahi and Abdulla ${ }^{(15)}$ found that the greater dimensional change was obtained at the mid palatal area compared to the crest of the ridge , but the deepest point 
of vestibule was not involved in their study. Teraoka and Takahashi ${ }^{(18)}$ found that the fit is more noticeable in the palate between the denture base and the cast, which agree with the current study.

\section{CONCLUSIONS}

The discrepancy of the adaptation of record base made from cold cured acrylic resin to the maxillary cast is greater than those made from heat cured acrylic resin. The observed discrepancy between the bench cure and the curing with thermopress is not significant. The greater dimensional change of the record base was measured at the deepest point of buccal vestibule of maxillary cast.

\section{REFERENCES}

1. Schoen PE ,Steart JL.The effect of temporary denture base on the accuracy of centric jaw relationship. J Prosthet Dent 1967; 53:53-55.

2. Yurktas AA, Kapur KK. Factors influencing centric relation records in edentulous patients. $J$ Prosthet Dent 1964; 14:1054-1065.

3. Matsurmra H, Tanue N, Kawasaki K, Atsuta M.Clinical evaluation of chmically cured hard denture lining material. $J$ Rehabil 2001; 28: 640-644.

4. Ahmad ZM. Evaluation of the effect of some denture cleansers on the color of acrylic resin denture base materials. M.Sc. thesis college of dentistry. University of Mosul. 2002.

5. Keenan PL, Radford DR, Clark RK. Dimensional change in complete dentures fabricated by injection molding and microwave processing. $J$ Prosthet Dent 2003; 89:37-44.

6. Consani RL, Domitti SS, Rizzatti CM. Effect of commercial acrylic resins on dimensional accuracy of the maxillary denture base. Braz Dent J. 2002; 13: 5760.

7. Consani RL, Domitti SS, Consani S. Effect of a new tension system, used in acrylic resin flasking, on the dimensional stability of denture base. $J$ Prosthet
Dent. 2002; 88: 285-289.

8. Sadamor S, Siswomihardjo W, Kameda K. Dimensional changes of relined denture base with heat cured, microwave activated, autopolymering, and visible light cured resins. A laboratory study. Aust Dent J. 1995; 40:322-326.

9. Mojon P, Oberholzer JP, MeyerJM, Belser UE. Polymerization shrinkage of index pattern acrylic resin. $J$ Prosthet Dent. 1990; 64: 684-688.

10. Sadoon MM. Evaluation repairing the acrylic resin base by using different materials design and technique. M.Sc. thesis. College of dentistry. University of Mosul.2004.

11. Pavan S, Arioli JN, Dossantos PH. Effect of microwave treatments on dimensional accuracy of maxillary acrylic resin denture base. Braz Dent J. 2005; 16: 119-123.

12. Consani RL, Domitti SS, Mesquita MF. Effect of packing types on the dimensional accuracy of denture base resin cured by the conventional cycle in relation to post-pressing times. Braz Dent $J$. 2004 ; 15: 63-67.

13. Machado AL, Vergani CE, Giampaolo ET. Effect of a heat-treatment on the linear dimensional change of a hard chairside reline resin. J Prosthet Dent. 2002; 88:611-615.

14. Mcabe JF. Anderson Applied Dental Materials. $6^{\text {th }}$ ed. Blackwell scientific puplication. 1985; Pp:83-92

15. Elahi JM, Abdullah MA. Effect of different polymerization techniques on dimensional stability of record bases. $J$ Prosthet Dent. 1994 ; 71:150-153.

16. Craige RG. Restorative Dental Materials. $10^{\text {th }}$ ed. St Louis, The CV Mosby Co. 1980; Pp : 380-381.

17. El sheikh H, Abdel-Hakim AM. Accuracy of freely adapted resin record bases. J Prosthet Dent. 1995; 73: 348-353

18. Teraoka F, Takahashi J. Controlled polymerization system for fabricating precise dentures. J Prosthet Dent. 2000; 83:514-520. 